\title{
SER BACHAREL E PROFESSOR: DILEMAS NA FORMAÇÃO DE DOCENTES PARA A EDUCAÇÃO PROFISSIONAL E ENSINO SUPERIOR
}

\author{
V. S. OLIVEIRA' e R. F. SILVA' \\ ${ }^{1}$ Instituto Federal do Rio Grande do Norte, ${ }^{2}$ Universidade Federal do Rio Grande do Norte \\ E-mail: viviufrn@yahoo.com.br ${ }^{1}$, rosa_lia_64@hotmail.com ${ }^{2}$
}

Artigo submetido em maio/2012 e aceito em maio/2012

\section{RESUMO}

O presente artigo discute sobre a formação de docentes bacharéis que atuam na Educação Profissional e no Ensino Superior, considerando o contexto social em que se configura atualmente, assim como apresenta os desafios existentes para a atuação de professores nesses campos de ensino. Partimos então da questão norteadora: Que desafios precisam ser enfrentados na formação de docentes para o campo da educação profissional e Superior? Desenvolvemos a temática proposta por meio de revisão bibliográfica assim como utilizamos parte dos estudos desenvolvidos em pesquisa mais ampla que resultou na publicação de uma tese sobre a docência exercida por bacharéis. Concluímos defendendo a sistematização da formação continuada como política de formação que decorre de acreditarmos que ela pode oferecer subsídios ao Ensino Superior e a Educação Profissional para que o professor consiga enfrentar o momento de crise e incertezas vivenciados nas suas experiências cotidianas, pois a busca de soluções diante dessas incertezas gera uma demanda por novas competências, novas habilidades e exigem que o docente esteja em contínuos estudos.

PALAVRAS-CHAVE: Docência, Ensino Superior, Educação Profissional.

\section{PROFESSORS WITH BACHELOR'S DEGREES: PROBLEMS IN EDUCATION TEACHER TRAINING AND HIGHER EDUCATION}

\begin{abstract}
The present article discusses teacher training of educators with only Bachelor's degrees who act as education professionals in institutions of Higher Education, considering the social context in which they currently perform, as well as presenting existing challenges in the performance of teachers within this context. We begin with the question: What challenges need to be confronted in teacher training programs for the field of education professionals and Higher? We developed this thematic approach based on a literature review, and including part of a study developed in a broader research project that resulted in the publication
\end{abstract}

of a doctoral dissertation about teaching on the part of educators with only Bachelor's degrees. Our conclusion defends the systemization of continuing education programs for teachers as basic training policy, as we believe that this systemization will benefit Higher Education and Professional Education, allowing professionals to overcome moments of crisis and insecurity experienced in their daily lives, finding solutions when faced with uncertainty generated by the need for new competencies, skills, and the need to meet the demands of professionals in continuing education programs.

KEY-WORDS: teaching, Higher Education, Professional Education. 


\section{SER BACHAREL E PROFESSOR: DILEMAS NA FORMAÇÃO DE DOCENTES PARA A EDUCAÇÃO PROFISSIONAL E ENSINO SUPERIOR}

\section{INTRODUÇÃO}

Desenvolver um estudo sobre a docência na Educação Profissional e Superior nos remete às preocupações vivenciadas pela educação de como podemos trabalhar com o conhecimento, desde as suas formas de organização, seus modos de ensino e aprendizagem dentre outros fatores que explicitam a complexidade de atuar como professores no contexto social atual.

Estamos vivenciando na atualidade uma era de tensões no campo educativo, tensões estas significativas que se configuram no trabalho com o saber: entre o global e o local, o universal e o particular, entre a tradição e o moderno, assim como as preocupações com o avanço do conhecimento e o tempo hábil de assimilação dos mesmos como, por exemplo, o desenvolvimento do conhecimento das novas tecnologias que mudam aceleradamente.

Na atualidade, as transformações expressivas nos setores sociais, políticos, econômicos e culturais tem demarcado uma palavra de ordem: mudança. Malusá e Feltran (2003) mostram que é nesse cenário de rápidas modificações sociais que se instala uma crise conceitual com relação aos saberes e habilidades que o professor, em todos os níveis de ensino, deve possuir.

Neste texto temos como objetivo discutir sobre a formação de docentes bacharéis que atuam na Educação Profissional (EP) e no Ensino Superior (ES), considerando o contexto social em que ela se configura atualmente, assim como apresentar os desafios existentes para a atuação de professores nesses campos de ensino. Partimos então da questão norteadora: Que desafios precisam ser enfrentados na formação de docentes para o campo da Educação Profissional e Ensino Superior?

Desenvolvemos a temática proposta por meio de revisão bibliográfica assim como utilizamos parte de estudos e pesquisas desenvolvidas por Oliveira (2011) sobre a formação de bacharéis que exercem a profissão docente. Buscando responder a questão proposta, na primeira seção deste texto apresentamos um cenário sobre a formação de docentes para o Ensino Superior e para o campo da Educação Profissional destacando as necessidades de formação pedagógica de bacharéis que atuam nesses campos como docentes. Na segunda seção, apresentamos uma discussão sobre os desafios da formação de bacharéis para o exercício da docência, buscando contribuir com um debate teórico-prático em torno dessa problemática e finalizamos pontuando os principais aspectos apresentados destacando perspectivas futuras de ampliação da discussão.

\section{O cenário da formação pedagógica do docente no Brasil}

O mundo na atualidade está se delineando pelos avanços das tecnologias e da ciência que influenciam diretamente em mudanças nos meios de comunicação, informação e no acesso ao conhecimento. Tais transformações têm influenciado vários segmentos sociais, provocando mudanças em contextos diferenciados e consequentemente na educação, no ensino, na produção científica e tecnológica. 
Pensando nessas transformações e nas exigências dessa configuração social, surge no âmbito das instituições de Ensino Superior de da Educação Profissional da rede federal à preocupação com a formação profissional, e conseqüentemente com a atuação de seus docentes.

Após alguns anos de estudo sobre a docência no Ensino Superior, em especial sobre bacharéis que atuam como docentes, consideramos que as problemáticas que se referem à formação de professores universitários se aproximam das que envolvem a formação do docente do campo da Educação profissional, por existir características semelhantes no perfil formativo e profissional dos bacharéis que atuam como professores nesses campos.

Considerando isto, a ampliação de nossas preocupações em compreender o processo formativo de docentes que atuam tanto no Ensino Superior quanto na Educação Profissional decorre do reconhecimento de que educar nesses campos "[...] significa ao mesmo tempo preparar os jovens para se elevarem ao nível da civilização atual, de sua riqueza de seus problemas, a fim de que aí atuem" (PIMENTA; ANASTASIOU, 2005, p.81).

Por isso, entende-se que o docente da Educação Profissional e Superior assume grandes responsabilidades na educação e formação profissional de seus alunos, afim de que eles possam estar preparados para enfrentar os desafios do mundo moderno. Para isso, espera-se que esse profissional reflita sobre suas ações e busque inovar suas práticas, aprimorando seus conhecimentos e práticas pedagógicas para que possam proporcionar uma formação crítica e atuando de forma que seus alunos possam exercer sua cidadania com base nos conhecimentos e habilidade apreendidos neste século XXI.

Ao defender a necessidade dos professores desenvolverem uma prática baseada na reflexão sobre a ação, Alarcão (2003, p.45) afirma que "na escola e nos professores, a constante atitude de reflexão manterá presente a importante questão da função que os professores e a escola desempenham na sociedade e ajudará a equacionar e resolver dilemas e problemas". A reflexão nesse sentido torna-se um elemento importante para o processo de formação e atuação docente, sendo também relevante essa postura nos âmbitos acadêmicos. A atitude reflexiva permite ao docente, outras possibilidades de ação e de formação, visando atender a necessidade social de uma formação que não privilegia somente os aspectos técnicos para o mundo do trabalho, mas também apresenta-se como humanística, integral incorporando ciência, trabalho, tecnologia e cultura como eixos indissociáveis.

Sendo assim, o docente deverá ser capaz de ajustar suas práticas e seus conhecimentos as novas exigências da sociedade, do aluno, dos diversos universos culturais, das formas de comunicação presentes, pois são esses seus elementos de trabalho que também sofreram e estão em constantes modificações.

Neste sentido, Libâneo (1998, p.10) acrescenta:

O novo professor precisaria, no mínimo de uma cultura geral mais ampliada, capacidade de aprender a aprender, habilidades comunicativas, domínio da linguagem informacional, saber usar meios de comunicação e articular com as mídias e multimídias. 
Os docentes de Ensino Superior e da Educação Profissional necessitam ter clareza de que seu conhecimento deve estar em constante resignificação, desenvolvendo uma postura de professor transformador que reflete sobre sua prática, questionando, pensando, criticando, buscando soluções, refazendo conceitos. Oliveira (2011) acrescenta que diante da sociedade da informação os docentes não podem oferecer aos discentes a mesma prática pedagógica que seus professores ofereceram em sua formação. Pois, as transformações e mudanças afetam toda a comunidade, até mesmo, em especial, o meio acadêmico.

Por isso destacamos a importância da formação pedagógica como pré-requisito para o exercício da docência, o que torna necessário a revisão das formas de admissão de novos professores nas Universidades e nos Institutos Federais de Educação, Ciência e Tecnologia. Muitas vezes o que se valoriza nos processos seletivos de admissão são os conhecimentos específicos do professor em relação a sua área de formação, bem como sua experiência profissional e titulações na área comum a de formação inicial.

Diante de todas essas mudanças sociais, a preocupação dessas instituições muitas vezes, refere-se apenas a sua titulação e produtividade, ficando, como argumenta Fernandes (1998, p.97) "o desempenho como professor sem reflexão sistematizada, que traga sua prática pedagógica como foco de análise, como sujeito dessa mesma prática". A docência parece, neste sentido, não ter espaço para o desenvolvimento de ações reflexivas sobre o seu fazer pedagógico.

Isto, conforme pesquisa de Oliveira (2011) decorre da ausência de formação pedagógica da maioria dos docentes universitários, e isto ocorre de forma semelhante na Educação Profissional, pois devido a formação inicial em cursos de bacharelado, naturalmente torna-se desconhecido aos docentes bacharéis os conhecimentos teórico/epistemológicos sobre os processos de ensino-aprendizagem.

Todavia, os problemas formativos dos profissionais em questão não se concentram apenas entre os bacharéis, pois nas licenciaturas também pode ser observado a existência de lacunas oriundas do "modelo $3+1$ " em que tradicionalmente foram organizados os currículos dos cursos, e neles, apenas no último ano de formação o licenciando tem contato com o estágio e com a atividade docente, enquanto os outros anos são dedicados a formação correspondente ao do bacharel.

Assim, o bacharel torna-se professor sem nenhum tipo de formação pedagógica e os licenciados por sua vez assumem a profissão com lacunas em seu processo formativo. Este fenômeno não é um problema que se limita aos Institutos Federais de Educação, Ciência e Tecnologia, nem apenas as Universidades Federais, pois o problema tem início na própria legislação que precisa ser mais enfática na necessidade dos conhecimentos didático-pedagógicos dos docentes que passam a compor os quadros funcionais dessas instituições, pois até o momento fica a critério e responsabilidade institucional proporcionar ou não cursos de formação continuada de curta duração aos ingressos no cargo de professor.

Sobre a formação docente, a Lei de Diretrizes e Bases para a Educação Nacional - LDB no 9.394/96, destaca que para a educação básica a formação 
Far-se-á em nível superior, em curso de licenciatura, de graduação plena, em universidades e institutos de educação, admitida, como formação mínima para o exercício do magistério na Educação Infantil e para as quatro primeiras séries do Ensino Fundamental, a oferecida e, nível médio, na modalidade normal (...). A preparação para o exercício do magistério superior far-se-á em nível de pósgraduação, prioritariamente em cursos de mestrado e doutorado (LDB, 1996, art. 62/65)

Apesar de a LDB apresentar a pós-graduação como espaço de formação do docente que atua no Ensino Superior, sobre a formação do docente da Educação Profissional não existe referência. Com relação a pós-graduação como espaço formativo do docente sabemos que nem sempre os cursos de mestrado e doutorado cumprem com esse objetivo, pois a pesquisa como parte integrante dessa formação ainda é privilegiada pelas instituições proponentes, fazendo com que as disciplinas de caráter didático-pedagógicas fiquem de fora de seus currículos, e quando são ofertadas, se limitam geralmente ao curso de Metodologias ou Didática do Ensino Superior.

Nesta perspectiva, a formação docente para a Educação Profissional e Superior fica a cargo das iniciativas individuais e institucionais esparsas, que não se referem a um projeto nacional ou da categoria docente, por isso existe a necessidade da sistematização de políticas de formação docente para ambos os campos de atuação.

O termo formação docente, na maioria das vezes, tem se apresentado como uma dificuldade de muitos professores, principalmente daqueles que por possuírem formação inicial em curso de bacharelados não obtiveram formação para a docência, ou mesmo aqueles que no período em que cursaram a pós-graduação, principalmente nos níveis de mestrado e doutorado, não participaram de formações voltadas para atuar como professor como é o caso de muitos bacharéis que atuam como docentes nas universidades e nos Institutos Federais de Educação, Ciência e Tecnologia. São esses profissionais que chamamos bacharéis-docentes, aqueles que sem uma formação didático-pedagógica para a docência tem exercido a profissão.

Álvares (2006) ao realizar pesquisa sobre a formação de professores engenheiros civis, afirma que a preocupação maior desses docentes que possuem formação em bacharelados e pósgraduação voltados para a ampliação de estudos mais técnicos da área, tem como foco principal o domínio de conteúdos de sua área profissional, e em muitos casos é deixado em segundo plano os aspectos pedagógicos do seu trabalho, ou seja, o exercício da profissão docente está quase sempre aliado à competência profissional como bacharel ou como pesquisador.

Reconhecemos que existem nas Universidades e nos Institutos Federais de Educação, Ciência e Tecnologia casos de profissionais com formações semelhantes a estes, que estão atuando em diferentes cursos. No entanto, não podemos colocar a culpa exclusivamente nesses profissionais pela sua falta de formação pedagógica para atuar na Educação Profissional e no Ensino Superior, pois, além de não a terem recebido durante o período de sua graduação ou pósgraduação, não existe exigência legal que a estabeleça como primordial para o exercício da docência nesses campos de atuação.

Como sabemos, a exigência é que se tenha a maior nível de formação específica na área de conhecimento em que vai atuar, e em muitos casos, no ambiente de trabalho, são poucos ou 
mesmo inexistentes os momentos e que os bacharéis participam de reflexão e formação continuada para o exercício da docência especificamente.

As Universidades e Institutos Federais de Educação, por mais que se preocupem com a questão, nem sempre tem desenvolvido ações no sentido de melhorar a qualidade do trabalho docente no que diz respeito aos aspectos pedagógicos da profissão. O que se promove institucionalmente são eventos como congressos, palestras, mesas-redondas com discussões sobre os temas que compõem as diversas áreas do conhecimento, os quais geralmente são organizados por área de atuação. Por isso, nos eventos que não tem o processo de ensino e a educação como foco principal, pouco se discute sobre questões que envolvam as práticas docentes (MASETTO, 2003).

O que podemos então perceber é que as Universidades e os Institutos Federais de Educação têm priorizado o domínio dos conhecimentos da área de formação dos bacharéis docentes bem como sua experiência profissional na área, proporcionando que, para tornar-se professor seja suficiente ter formação inicial, ser um bom profissional e ter uma sólida experiência na sua área de atuação.

Nesse sentido, os conhecimentos específicos da docência que são de igual importância para a atuação como professores profissionalmente são menos considerados, ficando em segundo plano como citamos anteriormente, colocando apenas sob a responsabilidade do tempo e do exercício da profissão o possível aprendizado da mesma, como se isso fosse possível exclusivamente por meio da prática.

Entretanto, Masetto (2003, p.13) mostra que atualmente, esse quadro começa a se modificar por iniciativa de muitos professores universitários que tem se preocupado com as formas como estão conduzindo sua prática e com a necessidade de possuírem formação específica para a docência que contemple os aspectos pedagógicos da profissão:

Só recentemente os professores universitários começaram a se conscientizar de que seu papel no Ensino Superior, como o exercício de qualquer profissão, exige capacitação própria e específica que não se restringe a ter um diploma de bacharel, ou mesmo de mestre ou doutor, ou ainda apenas o exercício da profissão. Exige isso tudo, e competência pedagógica, pois ele é um educador.

Isto nos conduz à percepção de que a responsabilidade de formação pedagógica dos docentes, em especial do bacharel docente, não deve estar apenas sob o desejo e iniciativa individual, mas acreditamos que deveria ser parte integrante do processo institucional de admissão e de desenvolvimento profissional por meio de formações continuadas de professores para a atuação na Educação Profissional e no Ensino Superior, pois sabemos que nesse processo de admissão, independente do nível de titulação que o professor apresente (graduação, mestrado, doutorado) o conhecimento das especificidades do ensino e da aprendizagem nessas áreas são imprescindíveis ao exercício docente.

Sendo assim, a luta pelo reconhecimento social da profissão docente que decorre de muitos anos, tem defendido que a docência é uma profissão que contém características próprias 
e que não deve ser exercida por pessoas sem formação adequada para a sua atividade. Na Educação Básica, a conquista pelo direito de que só pode atuar aquele que possua formação para a docência proporcionou avanços significativos na educação brasileira e os índices de qualificação profissional docente têm aumentado a cada ano. Hoje podemos observar que a quantidade de professores com formação superior na Educação Básica está crescendo significativamente, e isto pode ser considerado por nós como um passo importante para a melhoria da qualidade da educação oferecida a nossa população.

Por isso, procuramos com esse estudo, explicitar a importância do desenvolvimento de ações de formação pedagógica a serem oferecidas pelas instituições citadas, para que seja possível amenizar as lacunas existentes na formação profissional dos bacharéis-docentes, e ainda, de por meio dessa formação levá-los a refletir sobre suas práticas, proporcionando a ampliação da compreensão dos saberes e habilidades quem envolvem a profissão de professor. Com isso, acreditamos estar contribuindo de alguma forma para que possa haver novas perspectivas para o desenvolvimento de uma práxis educativa reflexiva na formação docente nas instituição federais de Ensino Superior e da Educação Profissional.

\section{Os desafios da Formação pedagógica de professores para Educação Profissional e Superior}

O trabalho do docente universitário e da Educação Profissional hoje se desenvolve principalmente por meio de estudos e pesquisas, do desenvolvimento e inovações pedagógicas, da orientação e avaliação dos alunos, da participação responsável na organização das propostas político-pedagógicas dos departamentos e cursos, orientação de alunos, na seleção de novos professores, na gestão acadêmica dentre outras tantas que desenvolvem para manter as atividades de uma instituição que oferece Ensino Superior (BENEDITO; FERRER; FERRERES, 1995).

Apesar dos concursos ainda enfatizarem os conhecimentos específicos de área mais do que os conhecimentos sobre a docência, estudos sobre a formação docente já apontam características que o professor deve obter para o exercício da profissão. Com base nas leituras de Anastasiou (2004) e reconhecendo as dimensões apresentadas por Grillo (2000) elenco alguns conhecimentos que somados aos conhecimentos de área de formação do bacharel são necessários ao docente de Ensino Superior e da Educação Profissional, tais como:

- Conhecimento dos fins sociais e educativos da instituição em que está vinculado;

- Inteligência interpessoal, na qual estão incluídas as habilidades nos relacionamentos interpessoais;

- inteligência relacional- como capacidade dos professores serem competentes na interação com o outro nos contextos em que estão inseridos;

- Conhecimento pedagógico- teorias e práticas que auxiliam no desenvolvimento da ação docente;

- Conhecimento do contexto - quem são seus alunos e em que espaço se desenvolve o ato educativo.

Considerando estes elementos como importantes ao professor, faz-se necessário que por meio da formação continuada ele possa rever suas ações e resignificar os sentidos que atribuem a 
docência como profissão. Considero que o debate sobre os sentidos de docência e as relações com a formação inicial não é algo necessário só na investigação sobre os bacharéis que atuam como professores, mas também aos licenciados, pois a identidade docente e seu desenvolvimento profissional se constroem em processo historicamente e em relação com as alteridades nos contextos em que estão inseridos.

Oliveira (2011) mapeia em sua pesquisa, lugares de formação da docência universitária e indicou que eles não tem se constituído com o reconhecimento da sua legitimidade, algo que compreendemos que também acontece na Educação Profissional. A formação do docente universitário fica à mercê da boa vontade de gestores ou de políticas desenvolvidas eventualmente e descontinuadas, e por isso são pouco reconhecidas no meio acadêmico. Existem inúmeros lugares formativos sendo assumidos, geralmente com duração temporária e pouco sistematizados institucionalmente. Considero, assim, essencial que as instituições de ensino incentivem a ampliação de seus espaços formativos para seus docentes. O contrário disto, conduz ao desempenho do profissional sem uma maior reflexão sistematizada ou dito de outra forma, um desempenho em que a sua prática pedagógica não se faz como foco de análise.

Diante dessas considerações, a ampliação dos espaços de formação constituem-se como desafios. Entre esses espaços destaco: os incentivos da pesquisa sobre a própria prática, a ampliação das discussões sobre a formação docente nos programas de pós-graduação, a ampliação da formação continuada institucional e a instituição de uma política de formação continuada para a docência de Ensino Superior e na Educação Profissional no interior das universidades e dos Institutos Federais.

- A pesquisa sobre a própria prática como espaço de autoformação

A pesquisa sobre a própria prática pode ser considerada como um espaço de formação porque alia a investigação ao ensino, submetendo-o ao exame crítico e ainda, auxilia o professor a encontrar soluções e conduzir a sua prática da melhor maneira possível resiginificando a relação teoria e prática no seu cotidiano.

As reformulações das formas de atuação docente podem ser feitas instituindo novas práticas fazendo com que a universidade alcance seus objetivos de oferecer uma formação de qualidade aos seus alunos. O professor, como investigador refletindo sobre a sua própria função como docente, amplia os conhecimentos sobre a sua ação profissional e, consequentemente, as instituições em que estes professores estão inseridos são beneficiadas por essa prática.

Alarcão (2003) aponta quatro razões para que os professores desenvolvam pesquisas sobre suas próprias práticas, sendo a primeira para que eles se assumam como protagonistas no campo curricular e profissional, passando a ter mais elementos para enfrentar os problemas emergentes desta mesma prática. A segunda razão expressa pela referida autora, refere-se a consideração de que esta é um modo privilegiado de desenvolvimento profissional e organizacional. Em terceiro lugar, a pesquisa sobre a própria prática contribui para a construção de um patrimônio do conhecimento sobre os professores como grupo profissional e por último, contribui para o conhecimento mais amplo sobre os problemas educativos.

Assim, os problemas oriundos emergentes da ação docente nos seus diversos níveis requerem do professor capacidades de problematização e investigação para além do bom senso 
e da boa vontade profissionais. A pesquisa sobre a própria prática não é algo que deve ser realizado de forma rotineira, sem investimento afetivo, pois o docente não deve partir do pressuposto de que é o cargo de professor na instituição que o torna um bom docente, mas o contrário, essa investigação requer o sentido de ser um protagonista social. Por isso, o docente deve assumir o compromisso nesse projeto de autoformação visando a transformação de sua prática e contribuir para a formação de novos paradigmas na sua ação como professor.

Pesquisar sobre a própria prática torna-se então um espaço de autoformação e beneficia o professor e aos alunos simultaneamente gerando conhecimentos, assim como desenvolve os saberes e competências como professor. A sala de aula como espaço de investigação possibilita ao docente universitário o conhecimento crescente sobre o ensino e aprendizagem em condições reais.

- A ampliação dos espaços de formação docente nos programas de pós-graduação

Se for observado os espaços existentes para a formação docente no Brasil, pode ser percebido que nos cursos de licenciaturas estão a responsabilidade da formação do profissional docente de educação básica, mas no que corresponde a formação do docente de Ensino Superior e da Educação Profissional esse é um espaço que necessita ser ampliado. Na universidade e nos Institutos Federais de Educação, Ciência e Tecnologia encontramos como desafio a ampliação de espaços de formação do docente nos programas de pós-graduação, em especial nos cursos stricto sensu.

Apesar da formação docente da Educação Superior no Brasil fazer parte dos objetivos dos programas de pós-graduação enunciados no parecer 977/65 da Câmara de Ensino Superior do Conselho Federal de Educação, de acordo com Soares e Cunha (apud OLIVEIRA, 2011), essa era uma preocupação da Coordenação de Aperfeiçoamento de Pessoal de Nível Superior- CAPES, no período inicial da implementação dos programas de pó-graduação, período em que os mestrados eram mais enfatizados que os cursos de doutorado no país. Entretanto, com o fortalecimento dos programas que passaram a oferecer o doutorado, o foco da atenção passou da formação da docência para a formação do pesquisador fazendo com que os saberes docentes tenham sido silenciados nos cursos de pós-graduação.

A concepção de que na formação do pesquisador está implícita a formação docente defendida nos Planos Nacionais de Pós-Graduação de responsabilidade da CAPES, passa pela perspectiva de que formando o pesquisador naturalmente se forma o professor. Esta afirmativa parte do princípio de que existe a indissociabilidade entre ensino e pesquisa. Isto é algo a ser refletido e discutido dentro dos programas de pós-graduação, pois como pode ser observado nos resultados de pesquisa de Oliveira (2011), no lugar da indissociabilidade está presente a fragmentação entre a pesquisa e o ensino, ou seja, os professores não estabelecem relação entre suas atividades de pesquisa com as de ensino.

Isto também pode ser visto nos registros de Oliveira (2011) quando afirmam que as atividades de ensino e pesquisa têm historicamente sendo trabalhadas de formas distintas e consequentemente a interação entre as mesmas não se concretiza espontaneamente, mas depende de vários fatores que envolvem principalmente as concepções de ensino e pesquisa dos próprios professores. Nesse contexto, a pós-graduação tem perdido cada vez mais o espaço de formação do professor, sendo pouco reconhecido pelos bacharéis a importância da pós- 
graduação para sua formação pedagógica, ficando contudo, a formação do pesquisador como maior contribuição neste nível de formação.

Assim, a formação do docente de Ensino Superior e Profissional no Brasil, na maior parte das vezes, fica sujeito às políticas institucionais por meio de pontuais ações de educação continuada. Para as autoras são raras as instituições que assumem claramente a importância dos saberes pedagógicos para os seus professores e se responsabilizam por iniciativas regulares nessa direção, incluindo as propostas pedagógicas de seus programas de pós-graduação stricto sensu.

Reconhecendo que a docência implica a atuação de profissionais de múltiplas áreas do conhecimento e formação profissional na profissão docente, faz-se necessário a ampliação das discussões sobre a obrigatoriedade das disciplinas pedagógicas nos cursos de pós-graduação stricto sensu, para que possa ser assegurado a este nível de ensino a possibilidade de profissionais com formação docente ainda que sejam bacharéis em sua formação inicial.

- A necessidade da instituição de uma política de formação continuada do docente universitário

Diante do desafio de ampliar os espaços formativos do docente para a Educação Profissional e Ensino Superior considerando a pesquisa sobre a própria prática como instrumento de autoformação, da importância da pós-graduação para formação do docente, reforçamos nesse momento a importância da instituição de uma política de formação continuada dos docentes para a atuação nos campos de pesquisa foco deste estudo.

Na busca de elementos que me auxiliassem a escrita sobre a importância da formação de políticas de formação do docente de Ensino Superior e Educação Profissional percebemos que muitas referências existentes tratam das políticas da formação do docente da educação básica. Assim, por exemplo, a Política Nacional de formação de professores, instituída em Diário Oficial da União de 30 de janeiro de 2009, que tem por finalidade proporcionar a formação continuada dos profissionais de magistério da educação básica. Entretanto, sobre a existência de uma política nacional de formação continuada dos docentes de Ensino Superior e da Educação Profissional ainda existe um silêncio, o que me faz perceber ser este um desafio que não se limita aos Institutos e Universidades Federais.

Na CAPES as políticas de formação continuada estão focadas nos cursos de atualização e de especialização dos docentes da educação básica, que tornaram-se de sua responsabilidade e são homologados por seu Conselho Técnico-Científico da Educação Básica. Dentre os pontos apresentados pela CAPES sobre esta política implementada em 2009, um dos destaques está no reconhecimento de que a formação docente para todas as etapas da educação básica é compromisso do Estado.

Sobre o ensino superior especificamente, na Própria Lei de Diretrizes e Bases da Educação Nacional - LDB no 9.394/96 é apresentada uma concepção de qualificação docente para o Ensino Superior onde os cursos de pós-graduação são considerados como formadores dos docentes e conforme apresentamos nem sempre os cursos cumprem com esse objetivo formativo, pois a pesquisa é parte integrante da qualificação profissional, mas não pode ser considerada como via única de qualificação. 
No decorrer de nossas leituras vimos que a LDB de no 9.394/96 não faz referência à formação pedagógica do docente nem de Ensino superior nem da Educação Profissional por isso, compreende-se como "silêncio" quanto a essa formação do professor desses campos de atuação. Isto faz com que a formação fique sob a iniciativa individual ou institucional de forma esparsa e o desafio é torná-la um projeto de âmbito nacional de formação de professores.

A defesa pela sistematização da formação continuada como política de formação decorre de acreditarmos que ela pode oferecer subsídios ao docente de Ensino Superior e da Educação Profissional para que ele consiga enfrentar o momento de crise e incertezas vivenciados nas suas experiências cotidianas, pois a busca de soluções diante das incertezas gera uma demanda por novas competências, novas habilidades e exigem que o docente esteja em contínuos estudos.

Com nossa experiência na docência de Ensino Superior consideramos importante, ainda que nossa formação acadêmica se volte para estudos sobre formação docente, estar continuamente estudando a partir do que temos vivenciado, das angústias, das necessidades de mudanças nas práticas que desenvolvemos, de rever alguns conceitos, de estarmos mais atentas e desenvolvermos nossa prática a partir do conhecimento dos alunos reais que temos e não a partir dos alunos ideais, de debater com os colegas os problemas existentes com as turmas, de tornar mais significativa a aprendizagem no ensino superior.

Os docentes como um todo, e não apenas os bacharéis necessitam fazer parte de uma instituição coletiva que discute e que renova suas práticas, atenta as necessidades da comunidade em que faz parte, buscando o que tanto se almeja: melhoria da qualidade de ensino oferecida e formação de profissionais que possam atuar e transformar os meios em que estão inseridos.

Ser bacharel e professor ao mesmo tempo torna-se um elemento essencial na contribuição com a formação dos seus alunos, principalmente, ao compartilhar com eles as experiências vivenciadas em sua área de atuação, pois como profissionais que possuem experiência no mundo do trabalho, podem desenvolver sua ação a partir dos desafios e das exigências que surgem. Eles trazem a realidade para a sala de aula e contribuem na formação dos discentes, mas a formação continuada é imprescindível e deve fazer parte de suas experiências.

A instituição da Política de Formação continuada do docente universitário e da Educação Profissional e o estímulo para que o docente desenvolva como projeto pessoal formar-se e profissionalizar-se como docente, contribuirá para ampliação dos saberes da docência e da possibilidade da ressignificação sobre suas práticas.

Dessa forma, indagar sobre o porquê da criação de Política de Formação de docentes da Educação Profissional e Superior constitui um grande desafio posto que, fazer da Instituição um espaço de formação onde os profissionais se proponham a refletir e ressignificar suas práticas, supõe debruçar-se sobre o aperfeiçoamento teórico e prático da sua própria formação como docentes, objetivando o exercício profissional de qualidade.

Diante do silêncio constatado em torno da existência de Políticas de Formação Continuada para a Educação Superior e da Educação Profissional, consideramos a partir do compromisso como educadoras que vivencia e reconhece a necessidade de Políticas dessa natureza em ambientes educacionais, a necessidade de propormos um conjunto de explicitações que podem vir a converter-se em pautas de discussões, em orientações de políticas formativas. 
Nestes termos e no âmbito do que temos refletido uma política comprometida com a qualificação da formação de professores no Ensino Superior e na Educação Profissional, poderá pleitear as seguintes pautas:

- Enquanto direito a ser pleiteado pela comunidade de professores, uma formação continuada de qualidade deve refletir o conjunto das necessidades dessa comunidade, como um compromisso de sujeitos históricos e envolvidos com seu processo formativo, sempre em construção;

- Emergindo das necessidades de sujeitos plurais, atores e autores do seu processo formativo, as proposições se perspectivarão em termos contemporâneos considerando as parcerias, as negociações democráticas, o debate criativo, além das inevitáveis tensões que emergirão dessas negociações;

- Como consequência dessa pluralidade e das configurações nas quais emergirão o debate como fonte criadora de uma Política de Formação, os investimentos feitos em conhecimentos, atividades e valores concernentes à formação, deverão ter como princípio e orientação o bem comum;

- As experiências formativas dos professores, suas implicações nos contextos acadêmicos bem como as experiências extra-muro da Instituição, constituirse-ão referências na construção/formalização de um corpus de conhecimento formativo fundamental à proposição de uma política de formação continuada;

- Os princípios estruturantes de uma política de formação continuada deverão se dirigir ao desenvolvimento de uma identidade profissional, que considere a docência como uma atividade complexa que envolve seres humanos e suas relações com os processos de ser, fazer, aprender e conviver;

- Os princípios norteadores de uma política de formação continuada considerará o ser em sua singularidade e em relação com os outros seres, com os espaços institucionais nos quais a formação se desenvolve, além dos contextos mais amplos, envolvendo o mundo em que os seres estão e vivenciam experiências inovadoras e criativas;

As considerações apresentadas nesta seção significam novos pontos de partida para o desenvolvimento de estudos sobre os espaços de formação do docente de Ensino Superior e da Educação Profissional. Compreendemos que estas são questões que afetam nosso cotidiano das universidades e nos Institutos Federais que ofertam Ensino Superior e que precisam de maior atenção e ampliação dos espaços de discussão. As ações desenvolvidas nas salas de aula e departamentos precisam ultrapassar os muros, devem ser debatidas e resignificadas por meio de ações coletivas desenvolvidas institucionalmente.

\section{Considerações finais}

No decorrer deste texto apresentamos a necessidade de ampliação dos espaços de formação do docente de Ensino Superior e da Educação Profissional considerando a necessidade da formação pedagógica em especial de bacharéis que exercem a atividade docente. A ampliação dos espaços de formação constitui-se como desafio. No decorrer do texto destacamos a importância da pesquisa sobre a própria prática, da ampliação dos Programas de Pós-Graduação, especialmente, de espaços de discussão nesses programas de formação para a docência, assim 
como defendemos a instituição de uma política de formação para a docência de Ensino superior e da Educação Profissional no interior das universidades e dos Institutos Federais.

Com base nas discussões apresentadas no decorrer deste texto, não temos como objetivo apresentar respostas imediatas, mas possibilitar novos questionamentos que possam conduzir a reflexão sobre as necessidades formativas de docentes que atuam nos campos da Educação Profissional e Superior. Ressaltamos a necessidade de ampliação estudos e pesquisas sobre a ação de bacharéis como professores, pois envolve a discussão sobre a sua profissionalização docente, que muitas vezes se apóia na própria experiência como aluno e profissional para exercer a docência como profissão. Por isso, a partir dos problemas que a própria ação dos bacharéis apresentam, podemos desconstruir e reconstruir dialogicamente o que eles pensam sobre ser professores, seus saberes e ações a partir de suas próprias situações de trabalho, e isto constitui-se como uma necessidade formativa.

\section{REFERÊNCIAS BIBLIOGRÁFICAS}

1. ALARCÃO, Isabel. Professor-investigador: Que sentido? Que formação? In: B. P. Campos (Org.), Formação profissional de professores no ensino superior. Porto: Porto Editora, Vol. 1, pp. 21-31, 2003.

2. ANASTASIOU, Léa das Graças Camargos. Profissionalização continuada: aproximações da teoria e da prática. In: BARBOSA, Raquel Lazzari Leite (org.). Trajetórias e perspectivas da formação de educadores. São Paulo: Editora UNESP, 2004.

3. BRASIL, Lei no 9.394, de 20 de dezembro de 1996 . Disponível em http://portal.mec.gov.br/arquivos/pdf/ldb.pdf, acessado em 10/01/2012.

4. GRILLO, M. O professor e a docência: o encontro com o aluno. In: ENRICONE, D. (Org.). Ser professor. Porto Alegre: EDIPUCRS, 2002.

5. LIBÂNEO, José Carlos. Adeus professor, adeus professora? Novas exigências educacionais e profissão docente. São Paulo: Cortez, 2001.

6. MALUSÁ, Silvana. Investigação Sobre a Atualização Docente no Ensino Superior Universitária. IN: MALUSÁ, Silvana \& FELTRAN, Regina Célia de S.(Org.) A Prática da Docência Universitária. São Paulo: Factash Editora, 2003. p.137-174.

7. MASETTO, Marcos T. Competência Pedagógica do Professor Universitário. São Paulo: Summus, 2003.

8. OLIVEIRA, Vivianne. S. de. Ser Bacharel e professor: sentidos e relações entre o bacharelado e a docência universitária. Tese (Doutorado em Educação). Universidade Federal do Rio Grande do Norte. Centro de Ciências Sociais Aplicadas. Programa de Pós-Graduação em Educação, 2011.

9. PIMENTA, Selma Garrido; ANASTASIOU, Léa das Graças Camargo. Docência no ensino superior. São Paulo: Cortez, 2005. 